\title{
ORIGINAL ARTICLE Prevalence of hypovitaminosis D and associated factors in obese Spanish children
}

\author{
T Durá-Travé ${ }^{1,2,3}$, F Gallinas-Victoriano ${ }^{2}$, MJ Chueca-Guindulain ${ }^{2,3}$ and S Berrade-Zubiri ${ }^{2,3}$
}

BACKGROUND/OBJECTIVES: Vitamin D deficiency may contribute to endocrine health and disease (diabetes, autoimmune thyroid diseases, polycystic ovarian syndrome, etc.). The aim of this study was to determine the prevalence and specific factors for hypovitaminosis D among children stratified by body mass index (BMI) in Northern Spain.

SUBJECTS/METHODS: A cross-sectional clinical (sex, age, season of study visit, place of residence and BMI) and blood testing (calcium, phosphorous, calcidiol and parathyroid hormone (PTH)) were accomplished in 546 Caucasian individuals (aged 3.2-15.8 years). The BMI (Z-score) allowed establishing four groups: normal, overweight, obesity and severe obesity. The criteria of the US Endocrine Society were used for the definition of hypovitaminosis D.

RESULTS: Calcidiol levels were significantly higher in normal and overweight groups $(P=0.001)$, whereas PTH levels were significantly higher in obesity and severe obesity groups $(P=0.001)$. Hypovitaminosis $D$ prevalence was significantly higher in severe obesity $(81.1 \%)$ and obesity $(68.2 \%)$ groups, whereas was lowest in overweight $(55 \%)$ and normal $(58.1 \%)$ groups $(P=0.001)$. There was a negative correlation between calcidiol and PTH levels $(P<0.01)$. Female $(90.9 \%)$, adolescent group (88,2\%), winter $(100 \%)$ and autumn (82.4\%) time and urban residence $(94.1 \%)$ imply a higher prevalence of hypovitaminosis D in subjects with severe obesity $(P<0.001)$. Female, puberal age, autumn, winter and spring time, urban residence and severe obesity were found to be independent predictors for hypovitaminosis $D$.

CONCLUSIONS: Severe obesity could be considered as an associated factor for vitamin D deficiency, and, owing to its high prevalence, the implementation of systematic screening and hypovitaminosis treatment programs would be particularly useful.

Nutrition \& Diabetes (2017) 7, e248; doi:10.1038/nutd.2016.50; published online 13 March 2017

\section{INTRODUCTION}

Vitamin D and parathyroid hormone (PTH) are well known because of their role in bone metabolism and calcium homeostasis. Vitamin D deficiency leads to less absorption of dietary calcium and increased PTH secretion to maintain normal levels of serum calcium. Vitamin D deficiency induces osteoclastic activity and contributes to loss of bone mineral density. ${ }^{1,2}$

Several observational studies have suggested that vitamin D deficiency may disrupt endocrine homeostasis in diabetes, autoimmune thyroid diseases and polycystic ovarian syndrome among others. Additional studies are needed to evaluate the underlying mechanisms. ${ }^{2,3-9}$

Gender, age, race, season of the year in which serum is collected, sun exposure and childhood obesity have been associated with lower levels of serum calcidiol. ${ }^{3,5,10-15}$ Vitamin D deficiency in obese individuals is attributed to several factors, such as decreased exposure to sunlight in obese subjects because of sedentary lifestyle, or to excessive vitamin sequestration within adipose tissue. ${ }^{2,3,11,16}$ Fractures, tibia vara and slipped capital femoral epiphysis are more common in obese children perhaps because of decreased bone density in a setting of vitamin $D$ deficiency. ${ }^{17}$ Thus, data on prevalence of vitamin $D$ deficiency among children, stratified by body mass index (BMI) categories (normal weight, overweight, obesity and severe obesity), may inform about the need for screening and treatment.
The aim of this study is to determine the prevalence and specific factors (sex, age group, season of the year in which blood sample was taken and place of residence) for vitamin D deficiency among children stratified by BMI in Northern Spain.

\section{MATERIALS AND METHODS}

Patients

We examined a cross-sectional study of 546 individuals ( 237 males and 309 females) aged 3.28 to 15.85 years who underwent a clinical examination and blood testing in the Pediatric Endocrinology Unit in the period January 2014-December 2014. Pubertal stage was determined in each patient according to Tanner's criteria, and patients were classified in two different groups: school group (Tanner stage I) and adolescent group (Tanner stages II-V). Place of residence was categorized as urban or rural ( $>$ or $<10000$ inhabitants, respectively).

The individuals were healthy white children in Navarra, Spain. They came from external consultations of the different pediatric subspecialties and no chronic pathologies that might affect growth, body composition, food ingestion or physical activity were detected previously. All patients who had received any medication (antiepileptic drugs or glucocorticoids) and vitamin D or calcium supplements were excluded.

\section{Clinical examination}

Weight and height measurements were made in underwear while barefoot. Weight was measured using an Año-Sayol scale (reading interval 0 to $120 \mathrm{~kg}$ and a precision of $100 \mathrm{~g}$ ), and height was measured using a

\footnotetext{
${ }^{1}$ Department of Pediatrics, School of Medicine, University of Navarra, Navarra Hospital Complex, Pamplona, Spain; ${ }^{2}$ Department of Pediatrics, Navarra Hospital Complex, Pamplona, Spain and ${ }^{3}$ Instituto de Investigación Sanitaria de Navarra (IdisNA), Pamplona, Spain. Correspondence: Professor T Durá-Travé, Department of Pediatrics, School of Medicine, University of Navarra, Navarra Hospital Complex, Avenue Irunlarrea, 4, Pamplona, Navarra 31008, Spain.
}

E-mail: tduratra@cfnavarra.es

Received 5 July 2016; revised 27 October 2016; accepted 1 November 2016 
Holtain wall stadiometer (reading interval 60 to $210 \mathrm{~cm}$, precision $0.1 \mathrm{~cm}$ ). The Z-score values for the BMI were calculated using the epidemiologic data contained whithin the program Aplicación Nutricional, from the Spanish Society of pediatric gastroenterology, hepatology and nutrition (Sociedad Española de Gastroenterología, Hepatología y Nutrición Pediátrica, available at http://www.gastroinf.es/nutritional/). The graphics from Ferrández et al. (Centro Andrea Prader, Zaragoza 2002) used as reference charts were included in (http://www.gastroinf.es/nutritional/).

The $Z$-score value for $\mathrm{BMI}$ allowed establishing the following groups:

Normal: Z-score between -1.0 (15th percentile) and +1.0 ( 85 th percentile). Overweight: $Z$-score $>1.0$ (85th percentile).

Obesity: Z-score $>2.0$ ( 97 th percentile).

Severe obesity: Z-score $>3.0$ (99th percentile).

\section{Blood testing}

Calcium, phosphorous and alkaline phosphatase plasma levels were measured during fasting by colorimetric methods using a COBAS 8000 analyzer (Roche Diagnostic, Mannheim, Germany). Intra- and interassay coefficients of variation were $<5 \%$.

Calcidiol was determined by a high-specific chemiluminiscence-immunassay (LIAISON Assay, Diasorin, Dietzenbach, Germany) with intra- and interassay coefficient of variation of $4.2-9.5 \%$ and $7.6-2.1 \%$, respectively, and functional sensitivity of $4.0 \mathrm{ng} \mathrm{ml}^{-1}$. PTH was determined by a highly specific solid-phase, two-site chemiluminescent enzyme-labeled immunometric assay using an Immulite analyzer (DPC Biermann, Bad Nauheim, Germany) with intra- and interassay coefficient of variation of 3.8-6.9\% and $3.1-7.2 \%$, respectively, and functional sensitivity of $5.0 \mathrm{pg} \mathrm{ml}^{-1} 18$

Vitamin D deficiency was defined as calcidiol lower than $20 \mathrm{ng} \mathrm{ml}^{-1}$ $\left(<50 \mathrm{nmoll}^{-1}\right)$. Vitamin $\mathrm{D}$ insufficiency is when calcidiol levels fluctuate between 20 and $29 \mathrm{ng} \mathrm{ml}^{-1}\left(50-75 \mathrm{nmol}^{-1}\right)$ and vitamin D sufficiency is when calcidiol levels reach or overtake $30 \mathrm{ng} \mathrm{ml}^{-1}\left(>75 \mathrm{nmoll}^{-1}\right) .^{19,20}$ Secondary hyperparathyroidism was defined when PTH serum levels exceed $65 \mathrm{pg} \mathrm{ml}^{-1} \cdot{ }^{12,21}$

\section{Statistical analysis}

Results are displayed as percentages (\%) and means (M) with corresponding standard deviations (s.d.) and confidence intervals $(95 \% \mathrm{Cl})$. The statistical analysis (descriptive statistics, Student's $t$-test, analysis of variance, $X^{2}$ test, Pearson's correlation and multiple logistic regression analysis) was performed using the program Statistical Packages for the Social Sciences version 20.0 (Chicago, IL, USA). Statistical significance was assumed when $P$-value was $<0.05$.

Parents and/or legal guardians were informed and provided verbal consent for the participation in this study in all cases. This study was approved by the Ethics Committee for Human Investigation at our institution (in accordance with the ethical standards laid down in the 1964 Declaration of Hensinki and later amendments).

\section{RESULTS}

The BMI distribution of the enrolled participants and/or the presumed risk factors for hypovitaminosis $D$ are summarized in Table 1. There were no significant differences between the distribution in relation to sex, season of blood sample and place of residence. However, the percentage of individuals suffering from obesity/severe obesity in the adolescent group was significantly higher with respect to the school group $(P=0.003)$.

Table 2 shows and compares the mean values for the clinical characteristics and biochemical determinations according to BMI

Table 1. Demographics of the study participants stratified by BMI status

\begin{tabular}{|c|c|c|c|c|c|}
\hline Items & Normal, n (\%) & Overweight, n (\%) & Obesity, n (\%) & Severe obesity, n (\%) & $\chi^{2}, \mathrm{P}$-value \\
\hline \multicolumn{6}{|l|}{ Sex } \\
\hline Male & $163(68.8)$ & $28(11.8)$ & $26(11.0)$ & $20(8.4)$ & 0.429 \\
\hline \multicolumn{6}{|l|}{ Age group } \\
\hline Childhood & $190(72.2)$ & $31(11.8)$ & $23(8.7)$ & $19(7.2)$ & 0.003 \\
\hline Adolescent & $165(58.3)$ & 38 (13.4) & 45 (15.9) & $35(12.4)$ & \\
\hline Summer & $46(67.5)$ & $8(11.8)$ & $4(5.9)$ & $10(14.7)$ & 0.625 \\
\hline Autumn & $118(65.2)$ & $26(14.4)$ & $20(11.0)$ & $17(9.44)$ & \\
\hline Winter & $112(64.4)$ & $21(12.1)$ & $24(13.8)$ & $17(9.8)$ & \\
\hline Spring & 79 (64.2) & 14 (11.4) & $20(16.0)$ & $10(8.1)$ & \\
\hline \multicolumn{6}{|l|}{ Residence } \\
\hline Rural & $124(65.3)$ & $27(14.2)$ & $20(10.5)$ & $19(10.0)$ & 0.694 \\
\hline
\end{tabular}

Table 2. Clinical and biochemical characteristics according to the BMl status (mean \pm s.d.)

\begin{tabular}{|c|c|c|c|c|c|}
\hline Items & Normal weight $(\mathrm{n}=355)$ & Overweight $(\mathrm{n}=69)$ & Obesity $(\mathrm{n}=68)$ & Severe obesity $(n=54)$ & $P$-value \\
\hline BMI (Z-score) & $-0.19 \pm 0.67$ & $1.37+0.29$ & $2.46+0.28$ & $4.65+2.24$ & 0.001 \\
\hline Phosphorus (mg dl ${ }^{-1}$ ) & $4.58+0.57$ & $4.62+0.55$ & $4.65+0.62$ & $4.53+0.71$ & 0.842 \\
\hline $\operatorname{ALP}\left(I U I^{-1}\right)$ & $234.92+81.36$ & $243.86+82.41$ & $253.21+91.16$ & $220.26+99.71$ & 0.253 \\
\hline PTH $\left(p g \mathrm{ml}^{-1}\right)$ & $31.09+15.94$ & $33.12+16.25$ & $39.89+20.56$ & $45.22+21.99$ & 0.001 \\
\hline Calcidiol $\left(\mathrm{ng} \mathrm{ml}^{-1}\right)$ & $28.09+7.68$ & $27.65+7.34$ & $26.18+7.00$ & $23.09+8.24$ & 0.001 \\
\hline
\end{tabular}




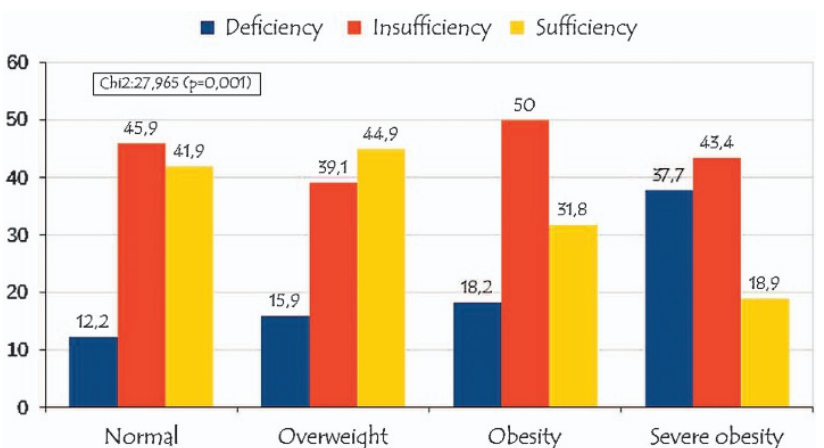

Figure 1. Prevalence of hypovitaminosis $\mathrm{D}$ in relation to the $\mathrm{BMI}$ status.

status. Calcidiol levels were significantly higher in normal and overweight groups $(P=0.001)$, whereas the mean values for PTH levels were significantly higher in obesity and severe obesity groups $(P=0.001)$. There were no significant differences in calcium, phosphate and alkaline phosphatase levels among the different groups according to BMI status.

Figure 1 depicts and compares the prevalence of hypovitaminosis $D$ in relation to the BMI status. Hypovitaminosis D prevalence (insufficiency and deficiency) was significantly higher in severe obesity (81.1\%) and obesity (68.2\%) groups, whereas the prevalence of hypovitaminosis $D$ was lowest in overweight (55\%) and normal (58.1\%) groups $(P=0.001)$. The frequency of hyperparathyroidism was significantly higher in severe obesity $(26.1 \%)$ and obesity $(9.1 \%)$ groups, whereas the prevalence of hyperparathyroidism was lowest in overweight (6.1\%) and normal (2.5\%) groups $(P=0.001)$.

There was a negative correlation $(P<0.01)$ between calcidiol and PTH levels $(r=-0.245)$. In addition, there was also positive correlation $(p<0.01)$ between PTH and BMI ( $Z$-score) $(r=0.268)$ and negative correlation $(P<0.01)$ between calcidiol and BMI (Z-score) ( $r=-0.198)$.

Females in a normal BMI status show a prevalence of sufficiency and deficiency in vitamin D of $37.7 \%$ and $11.5 \%$, respectively, and those females in a condition of severe obesity present with a prevalence of sufficiency and deficiency of $9.1 \%$ and $39.4 \%$, respectively $(P=0.001)$. There were no significant differences among males $(P=0.079)$. Within the adolescent group, those in a normal BMI status showed a prevalence of sufficiency and deficiency of $34.1 \%$ and $15.9 \%$, respectively, and those with severe obesity showed $11.8 \%$ and $44.1 \%$, respectively $(P=0.004)$. There were no significant differences within the school group $(P=0.338)$. In winter time, prevalence of sufficiency and deficiency for individuals with normal BMI status was $44.6 \%$ and $19.6 \%$, respectively, whereas the prevalence for those with severe obesity was $0 \%$ and $47.1 \%$, respectively $(P=0.006)$. In the summer time, the prevalence of sufficiency and deficiency for individuals in a normal BMI status was $84.4 \%$ and $4.4 \%$, respectively, whereas the prevalence for those individuals with severe obesity was $50 \%$ and $20 \%$, respectively $(P=0.047)$. In autumn, the prevalence of sufficiency and deficiency for individuals in normal BMI status was $35.6 \%$ and $7.6 \%$, respectively, whereas the prevalence in individuals with severe obesity was $17.6 \%$ and $52.9 \%$, respectively $(P=0.001)$. There were no significant differences in spring time $(P=0.821)$. Within the group of urban residence, the prevalence of sufficiency and deficiency in vitamin D for individuals in a normal BMI status was $38.2 \%$ and $14.5 \%$, respectively, whereas the prevalence for those individuals suffering from severe obesity was $5.9 \%$ and $47.1 \%$, respectively $(P=0.001)$. There were no significant differences in the group of rural residence $(P=0.238)$.

The multiple logistic regression analysis for the presumed predictors of vitamin D status is represented in Table 3. Female
Table 3. Multiple logistic regression analysis for presumed risk factors for hypovitaminosis D

\begin{tabular}{|c|c|c|c|c|}
\hline \multirow[t]{2}{*}{ Characteristics } & \multicolumn{2}{|l|}{ Deficiency } & \multicolumn{2}{|l|}{ Insufficiency } \\
\hline & OR $(95 \% \mathrm{Cl})$ & P-value & OR $(95 \%$ Cl) & P-value \\
\hline \multicolumn{5}{|l|}{ Sex } \\
\hline Male & Referent & & Referent & \\
\hline Female & $1.07(0.75-1.76)$ & 0.788 & $1.66(1.13 .2 .3)$ & 0.009 \\
\hline \multicolumn{5}{|l|}{ Age group } \\
\hline Children & Referent & & Referent & \\
\hline Adolescents & $1.91(1.14-3.19)$ & 0.013 & $1.93(1.31-2.48)$ & 0.001 \\
\hline \multicolumn{5}{|c|}{ Season of study visit } \\
\hline Summer & Referent & & Referent & \\
\hline Autumn & $3.54(1.25-10.9)$ & 0.027 & $9.33(4.57-19.03)$ & 0.001 \\
\hline Winter & $4.81(1.59-14.87)$ & 0.006 & $8.5(4.15-17.41)$ & 0.001 \\
\hline Spring & $2.35(0.71-7.71)$ & 0.158 & $12.55(5.85-26.95)$ & 0.001 \\
\hline \multicolumn{5}{|l|}{ Residence } \\
\hline Rural & Referent & & Referent & \\
\hline Urban & $2.35(1.22-3.85)$ & 0.020 & $1.73(1.49-2.09)$ & 0.01 \\
\hline \multicolumn{5}{|l|}{$B M I$} \\
\hline $\begin{array}{l}\text { Normal } \\
\text { weight }\end{array}$ & Referent & & Referent & \\
\hline Overweight & $1.34(0.63-2.8)$ & 0.438 & $0.77(0.44-1.36)$ & 0.476 \\
\hline Obesity & $1.27(0.61-2.64)$ & 0.514 & $1.13(0.62-2.07)$ & 0.498 \\
\hline $\begin{array}{l}\text { Severe } \\
\text { obesity }\end{array}$ & $4.32(2.15-8.68)$ & 0.001 & $4.23(1.81-9.89)$ & 0.001 \\
\hline
\end{tabular}

Abbreviations: $\mathrm{BMI}$, body mass index; $\mathrm{Cl}$, confidence interval; $\mathrm{OR}$, odds ratio.

gender, adolescent age, season of blood sample taken (autumn, winter and spring), urban residence and severe obesity were associated with an increased risk of vitamin D insufficiency. Furthermore, adolescent age, season of blood sample was taken (autumn and winter), urban residence and severe obesity were associated with an increased risk of vitamin D deficiency.

\section{DISCUSSION}

Sex, age, season of the year and place of residence have been described as independent factors as it was associated with hypovitaminosis $D,{ }^{3,5,10-15}$ as indicated by the results of logistic analysis in this study; however, in this case, the analysis did not detect significant differences in the distribution of nutritional status in relation to this factors, except for a different proportion of individuals with obesity/severe obesity in the adolescent group, which was slightly higher. On the other hand, owing to the importance of geographical location and weather conditions in the cutaneous synthesis of vitamin $D, 3,12,21-25$ it should be emphasized that Navarre is a Spanish region located in the north of the lberian peninsula and characterized by a high frequency of precipitations and/or cloudiness and high latitude $\left(42^{\circ}\right.$ north latitude), and these features could condition the levels of serum calcidiol.

Individuals with severe obesity showed relatively lower mean levels of calcidiol when compared with other BMI status (normal, overweight and obesity). The results display mean values for calcidiol decreasing substantively as BMI (Z-score) increases: from mean values of $28.2 \mathrm{ng} \mathrm{ml}^{-1}$ in a normal nutritional situation to $23.1 \mathrm{ng} \mathrm{ml}^{-1}$ in patients with severe obesity. In addition, a negative association between calcidiol and BMI (Z-score) is observed, as reported previously. ${ }^{3,5,10,13}$ On the other hand, individuals with obesity and severe obesity exhibit mean PTH 
values significantly higher than individuals in normal BMI status and/or overweight. In fact, mean values for PTH substantively increase as BMI (Z-score) rises: from mean values of $31.1 \mathrm{pg} \mathrm{ml}^{-1}$ in those individuals with normal BMl status to $45.2 \mathrm{pg} \mathrm{ml}^{-1}$ in those individuals with severe obesity; therefore, there appears to be a positive association between PTH and BMI (Z-score). This means, a clear tendency to show low calcidiol levels and increased PTH levels in severe obesity in relation to other nutritional situations is detected; in this way, other authors have highlighted that this condition might constitute a metabolic and/or cardiovascular risk factor. $2,4-6,10,13,14,16,26,27$

This reduction in the levels of serum calcidiol coinciding with increased adiposity is assumed to be due to enhanced sequestration of vitamin $D$ in fat, a factor leading to decreased bioavailability. 2,3,11,16,28 Consequently, lower serum calcidiol in obesity stimulates a rise in PTH, which in turn stimulates the renal hydroxylation of calcitriol and this condition elevates calcium influx into adipocytes. Intracellular calcium promotes lipogenesis and potentially reduces catecholamine-induced lipolysis. ${ }^{16}$ In fact, PTH has been postulated as an independent predictor of obesity; however, this hypothesis has been considered highly controversial, as weight loss in these individuals is associated with a normalization of vitamin D and PTH serum levels; that means, it rather seems as a consequence, not a cause, of excess body weight. ${ }^{10}$

Authors do not generally distinguish between obesity and severe obesity, as we have done in this work, and this detail could be of practical concern, mainly if we take into account that the logistic regression analysis determined how hypovitaminosis D status, both insufficiency and deficiency, was significantly associated with severe obesity.

In general, calcidiol concentrations below $20 \mathrm{ng} \mathrm{ml}^{-1}$ are considered to indicate vitamin D deficiency, whereas levels between 20 and $30 \mathrm{ng} \mathrm{ml}^{-1}$ indicate a relative insufficiency, and levels of $30 \mathrm{ng} \mathrm{ml}^{-1}$ or greater indicate sufficient vitamin D. ${ }^{19,20}$ In this cross-sectional study, $56.8 \%$ of subjects with normal BMI status had suboptimal calcidiol levels $\left(<30 \mathrm{ng} \mathrm{ml}^{-1}\right)$ and $11.8 \%$ were vitamin D deficient (defined as calcidiol $<20 \mathrm{ng} \mathrm{ml}^{-1}$ ). In contrast, the percentage of hypovitaminosis in individuals with severe obesity was $81.1 \%$ (insufficiency: $43.4 \%$ and deficiency: $37.7 \%$ ). This means, individuals with severe obesity show a higher trend to present with vitamin D deficiency in comparison with other BMl status (normal, overweight and obesity), probably in relation to a more sedentary lifestyle and, consequently, a decreased sun exposure, and also to limited bioavailability of vitamin D caused by trapping in adipose tissue. These results, even when considered as high rates of hypovitaminosis $\mathrm{D}$, are relatively moderate rates with respect to other published studies; $3,11,13,14,21,29-31$ this fact may be due to the white race of such individuals, as, as it is well known, the difference in skin pigmentation in different ethnic groups implies a higher risk of hypovitaminosis D. ${ }^{11,12,21,32}$

The analysis of the different factors associated to hypovitaminosis D (sex, age group, season of the year and place of residence) in relation to the different BMI status nutritional situations confirms that individuals with severe obesity show a higher tendency to vitamin D deficiency in females as well as in puberty, autumn and winter time and residence in an urban area with respect to the other BMI status. Nevertheless, the location of the residence in rural areas was not associated with a higher risk of suffering from vitamin D deficiency among the different BMI status. This finding would support the hypothesis that lifestyles (active outdoor life and sun exposure in rural areas) would be determining in the explanation of the differences among calcidiol serum levels and/or the prevalence of hypovitaminosis D.

Our study has several limitations, such as its cross-sectional nature and the absence of data about exercise, sun exposure and use of sunscreens. The difficulties in obtaining an adequate and accurate data collection deterred us from accomplishing the registration. A nutritional survey (dietary vitamin D intake, daily vitamin D supplementation, etc.) was not included. Our experience indicates that dairy product consumption in our environment is below the recommended amount, and fish consumption is very low among pediatric population, ${ }^{33}$ and only the dietary supplementation of vitamin D could condition the results obtained, but this is not an extended practice in our society.

In conclusion, severe obesity could be considered as a factor associated with vitamin D deficiency, and, owing to its high prevalence, the implementation of systematic screening and hypovitaminosis treatment programs would be particularly useful.

\section{CONFLICT OF INTEREST}

The authors declare no conflict of interest.

\section{ACKNOWLEDGEMENTS}

The authors received no financial support for the research, authorship and/or publication of this article (none declared).

\section{AUTHOR CONTRIBUTIONS}

TDT and FGV participated in study design and data analysis, and wrote the first draft of the manuscript. MJCG and SBZ participated in data collection and analysis. All authors participated in manuscript preparation and approved its final version.

\section{REFERENCES}

1 Holick MF. Vitamin D deficiency. N Engl J Med 2007; 357: 266-281.

2 Palermo NE, Holick MF. Vitamin D, bone health, and other health benefits in pediatric patients. J Pediatr Rehabil Med 2014; 7: 179-192.

3 Alemzadeh R, Kichler J, Babar G, Calhoun M. Hypovitaminosis D in obese children and adolescents: relationship with adiposity, insulin sensitivity, ethnicity, and season. Metabolism 2008; 57: 183-191.

4 Roth CL, Elfers C, Kratz M, Hoofnagle AN. Vitamin d deficiency in obese children and its relationship to insulin resistance and adipokines. J Obes 2011; 2011: 495101.

5 Pacífico L, Anania C, Osborn JF, Ferraro F, Bonci E, Olivero E et al. Low 25(OH)D3 levels are associated with total adiposity, metabolic syndrome, and hypertension in Caucasian children and adolescents. Eur J Endocrinol 2011; 165: 603-611.

6 Olson ML, Maalouf NM, Oden JD, White PC, Hutchison MR. Vitamin D deficiency in obese children and its relationship to glucose homeostasis. J Clin Endocrinol Metab 2012; 97: 279-285.

7 Mezza T, Muscogiuri G, Sorice GP, Prioletta A, Salomone E, Pontecorvi A et al. Vitamin D deficiency: a new risk factor for type 2 diabetes? Ann Nutr Metab 2012; 61: 337-348.

8 Muscogiuri G, Mitri J, Mathieu C, Badenhoop K, Tamer G, Orio F et al. Mechanisms in endocrinology: vitamin $\mathrm{D}$ as a potential contributor in endocrine health and disease. Eur J Endocrinol 2014; 171: 101-110.

9 Navarro-Valverde C, Quesada-Gomez JM. Vitamin D, determinant of bone and extrabone health. Importance of Vitamin D supplementation in milk and dairy products. Nutr Hosp 2015; 31: 18-25.

10 Reinehr T, de Sousa G, Alexy U, Kersting M, Andler W. Vitamin D status and parathyroid hormone in obese children before and after weight loss. Eur $J$ Endocrinol 2007; 157: 225-232.

11 Turer CB, Lin H, Flores G. Prevalence of vitamin D deficiency among overweight and obese US children. Pediatrics 2013; 131: e152-e161.

12 Vierucci F, Del Pistoia M, Fanos M, Gori M, Carlone G, Erba P et al. Vitamin D status and predictors of hypovitaminosis $D$ in Italian children and adolescents: a crosssectional study. Eur J Pediatr 2013; 172: 1607-1617.

13 Bellone S, Esposito S, Giglione E, Genoni G, Fiorito C, Petri A et al. Vitamin D levels in a paediatric population of normal weight and obese subjects. J Endocrinol Invest 2014; 37: 805-809.

14 Gutierrez-Medina S, Gavela-Pérez T, Domínguez-Garrido MN, Blanco-Rodríguez, Garcés C, Rovira A et al. Elevada prevalencia de déficit de vitamina D entre los niños y adolescentes obesos españoles. An Pediatr (Barc) 2014; 80: 229-235.

15 Radhakishun N, van Vliet M, von Rosenstiel I, Weijer O, Diamant M, Beijnen J et al. High prevalence of vitamin D insufficiency/deficiency in Dutch multi-ethnic obese children. Eur J Pediatr 2015; 174: 183-190.

16 Smotkin-Tangorra M, Purushothaman R, Gupta A, Nejati G, Anhalt H, Ten S. Prevalence of vitmina $D$ insufficiency in obese children and adolescents. $J$ Pediatr Endocrinol Metab 2007; 20: 817-823. 
17 Dimitri P, Bishop N, Walsh JS, Eastell R. Obesity is a risk factor for fracture in children but is protective against fracture in adults: a paradox. Bone 2012; 50: 457-466.

18 Enko D, Fridrich L, Rezanka E, Stolba R, Ernst J, Wendler I et al. 25-Hydroxy-vitamin D status: limitations in comparison and clinical interpretation of serum-levels across different assay methods. Clin Lab 2014; 60: 1541-1550.

19 Holick MF, Binkley NC, Bischoff-Ferrari HA, Gordon CM, Hanley DA, Heaney RP et al. Endocrine Society. Evaluation, treatment, and prevention of vitamin $D$ deficiency: an Endocrine Society clinical practice guideline. J Clin Endocrinol Metab 2011; 96: 1911-1930.

20 Holick MF, Binkley NC, Bischoff-Ferrari HA. Guidelines for preventing and treating vitamin D deficiency and insufficiency revisited. J Clin Endocrinol Metab 2012; 97: 1153-1158.

21 Weng FL, Shults J, Leonard MB, Stallings VA, Zemel BS. Risk factors for low serum 25-hydroxyvitamin $D$ concentrations in otherwise healthy children and adolescents. Am J Clin Nutr 2007; 86: 150-158.

22 Sullivan SS, Rosen CJ, Halteman WA, Chen TC, Holick MF. Adolescent girls in Maine are at risk for vitamin D insufficiency. J Am Diet Assoc 2005; 105: 971-974.

23 Willis CM, Laing EM, Hall DB, Hausman DB, Lewis RD. A prospective analysis of plasma 25 -hydroxyvitamin $D$ concentrations in white and black prepubertal females in the southeastern United States. Am J Clin Nutr 2007; 85: 124-130.

24 Gill TK, Hill CL, Shanahan EM, Taylor AW, Appleton SL, Grant JF et al. Vitamin D levels in an Australian population. BMC Public Health 2014; 14: 1001.

25 Vierucci F, Del Pistoia M, Fanos M, Erba P, Saggese G. Prevalence of hypovitaminosis $D$ and predictors of vitamin $D$ status in Italian healthy adolescents. Ital J Pediatr 2014; 40: 54.

26 Reis JP, von Mühlen D, Miller ER III, Michos ED, Appel LJ. Vitamin D status and cardiometabolic risk factors in the United States adolescent population. Pediatrics 2009; 124: e371-e379.
27 Alemzadeh R, Kichler J. Parathyroid hormone is associated with biomarkers of insulin resistance and inflammation, independent of vitamin D status, in obese adolescents. Metab Syndr Relat Disord 2012; 10: 422-429.

28 Lenders CM, Feldman HA, Von Scheven E, Merewood A, Sweeney C, Wilson DM et al. Relation of body fat indexes to vitamin D status and deficiency among obese adolescents. Am J Clin Nutr 2009; 90: 459-467.

29 Harkness L, Cromer B. Low levels of 25-hydroxy vitamin D are associated with elevated parathyroid hormone in healthy adolescent females. Osteoporos Int 2005; 6: 109-113.

30 González-Gross M, Valtueña J, Breidenassel C, Moreno LA, Ferrari M, Kersting M et al. Vitamin D status among adolescents in Europe: the Healthy Lifestyle in Europe by Nutrition in Adolescence study. Br J Nutr 2012; 107: 755-764.

31 Bener A, Al-Ali M, Hoffmann GF. Vitamin D deficiency in healthy children in a sunny country: associated factors. Int J Food Sci Nutr 2009; 60: 60-70.

32 Rovner AJ, O'Brien KO. Hypovitaminosis D among healthy children in the United States: a review of the current evidence. Arch Pediatr Adolesc Med 2008; 162: 513-519.

33 Durá-Travé T, Gallinas-Victoriano F. Dietary pattern among schoolchildren with normal nutritional status in Navarre, Spain. Nutrients 2014; 6: 1475-1487.

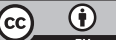

This work is licensed under a Creative Commons Attribution 4.0 International License. The images or other third party material in this article are included in the article's Creative Commons license, unless indicated otherwise in the credit line; if the material is not included under the Creative Commons license, users will need to obtain permission from the license holder to reproduce the material. To view a copy of this license, visit http://creativecommons.org/licenses/ by/4.0/

(c) The Author(s) 2017 